Studia UBB 阷igitalia, Volume 62 (LXII) 2017, June, Issue 1, 75-82

Published Online: 2017-06-30

DOI:10.24193/subbdigitalia.2017.1.05

\title{
Media archaeology of institutional archives?
}

\author{
Gábor Palkó \\ Petőfi Literary Museum, Budapest, Hungary, \\ E-mail: luhpeg@gmail.com
}

\begin{abstract}
In his book entitled What is media archaeology Jussi Parikka suggests that it is possible to outline and develop a 'hardcore' media archaeology not only of the hard drive and software but their official use as a database, as information management systems as well. But is it possible at all to give a media archaeological account of the formal-institutional digital media practices, to provide a deep and material media archaeology of, say, a scholarly text archive as TextGrid or Deutsches Textarchiv? In my paper I try to check the ability of Parikka's argument to answer these questions.
\end{abstract}

Keywords: media archaeology; archive.

Jussi Parikka in his book entitled What is media archaeology starts the chapter focusing on digital heritage and software culture with a rather well-known statement in the discourse of media theory. Let's take a look at this statement and its possible contexts outside media archaeology.

"Immediacy is the shadow side of mediation" (Parikka 2012 113.) Or to quote the book entitled Remediation by Bolter and Grusin Parikka refers to here directly: "the logic of immediacy dictates that the medium itself should disappear and leave us in the presence of the thing represented." (Bolter and Grusin 5) To put it yet another way: the more effective a media does its job, the more invisible it gets, cherishing the illusion that content is flowing through the mediating channel untouched.

This may easily send us to Marshal McLuhan's famous statements - Bolter and Grusin in the above-mentioned book refer to Understanding Media by the title already: Understanding New Media. At the same time, the phrase 'shadow side' may also bring to mind Boris Groys and his brilliant essay on the sub-medial space of the archive (Groys) - all the more so since Parikka in the respective chapter mentions a media archaeological gaze on the archive and its invisible, hidden mediality. 
I quote Parikka: "Media archaeology starts with the archive - the implicit starting point for so much historical research that it itself, as a place and a media form, has been neglected, become almost invisible." (Parikka 2012 113) Arlette Farge, a scholar who has spent decades with historical research in the physical space of the archive sometimes feels the urge to reflect on it as a media form, in order to make the institute itself visible. Wolfgang Ernst, an emblematic figure of media archaeology, takes notices of Farge when discussing the archive in his Rumoren essay (Ernst 2002). Parikka neglects the wonderful, highly metaphorical and yet still very tangible lines of The Allure of the Archives (Farge) - and he does it not juts here.

But what does it mean that "Media archaeology starts with the archive?" Parikka, Erns and media archaeology in general refers to and expands Foucault's notion of the archive, which is a modification that goes back to Kittler:

The centrality of the archive for any cultural and media archaeology is to a large extent a follow-up to Foucault's expansion of the concept from the concrete physical places of storage of cultural data to the discourses that govern modes of thinking, acting and expression. (Parikka 2012 113)

And:

Kittler was adamant that we need to make sure that Foucault's understanding of what governs our contemporary life-its archive-is not only about the statements and rules found in books and libraries. Instead, it is to be found in technological networks of machines and institutions, patterns of education and drilling: in the scientific-engineering complex that practices such forms of power that the traditional humanities theory is incapable of understanding or grasping if it continues to talk about hermeneutic meanings or persists to operate with traditional sociological concepts. (Parikka 2015 2)

The "methodology" of media archaeology for both Wolfgang Ernst and Jussi Parikka means a gesture towards bringing the shadow side of the medium into light, or to put it another way, towards shedding light on the invisible, sub-medial substrata of the medium by scrutinizing technological networks of machines and institutions. We do not risk too much when we state that this gesture or method is of vital importance in the case of digital heritage. If Manuel Castells is right and culture as such is delivered through the digital medium to the user of network society (this is what is described by Castells through the chiastic notion of real virtuality that overwrites and expands the term virtual reality), so if culture is digitally mediated today, then the gesture to expose the shadows of digital mediation is a prerequisite to understand present culture as such. 
To cite ta famous paragraph from Castells: "All messages of all kinds become enclosed in the medium because the medium has become so comprehensive, so diversified, so malleable that it absorbs in the same multimedia text the whole of human experience, past, present, and future." (Castells 404)

Parikka really goes into the shadowy depth of this medium of 'multimedia text' in his above-mentioned chapter on digital heritage. In my paper, I will try to show what models he uses to bring the dark side into the light.

Parikka states, that:

the archive has been a key node in relaying and storing data of modern culture, and hence acted as a key medium in itself - very much connected to the bureaucratic mode of control alongside registering and manipulating data, primarily in offices and through office technologies: typewriters, calculators, spreadsheets, carbon copies and, later, databases, software-based applications, etc. In various accounts of media history, computers themselves are regarded as part of the lineage from papyrus to paper, to printing and the need for advanced information management systems to organize the massive amount of printed materials $(. .$.$) the database is the primary form of organizing and expressing$ reality fits the same bill: instead of the narrative, the structural collections of data we call databases form new kinds of information realities enabled by computers. (Parikka 2012 114)

This quote triggers high expectations by referring to the media archaeological research of Cornelia Vismann who discloses in a breathtakingly meticulous manner the material factors behind bureaucratic control and governance, while situating them in a media historical context. The digital heritage, or as the 'GLAM' institutions (Galleries, Libraries, Archives, Museums) call them in an EU project phraseology: digital cultural heritage $(\mathrm{DCH})$, as it misses materially oriented and media theoretical reflection, in its mediality stays in the shadow. Is it possible to crack the black box of DCH open? (Here I refer to Parikka's words from his Geology-book: cracking open the black box of historical archives. (Parikka 2015 147, 150)).

Parikka's argument (in this chapter and elsewhere as well) suggests that it is possible to outline and develop a Vismann-ian 'hardcore' media archaeology not only of the hard drive and software, but their official use as a database, as information management systems as well. The question arises: can we find any trace of such an effort in Vismann's Law and Media Technology evoked here by Parikka, the book that focuses on analogue bureaucratic, archiving and governance practices? Yes and no. Although the whole initiative of dealing with the material practices of handling files is contextualized by the "ubiquitous promise of the paperless office" of electronic data 
procession (Vismann 12), she only emphasizes the possible similarity between the analogue and the digital file management in her last short chapter. There is no doubt, that it is interesting and fruitful to state that: "The history of files therefore also contains a prehistory of the computer." But from this perspective we certainly won't expect the unveiling of medial specificity of the electronic data processing. And Vismann's early death deprives us of the hope that she will augment her media archaeological analysis to the digital world. What is at stake in the sixth chapter of What is Media Archaeology is exactly this move from the analogue to the digital file. But before we try to understand in what way Parikka continues Vismann's venture, let's go back to Vismann and to her few remarks on the electronic medium. She tries to legitimize her focus on the material history of the bureaucratic file-handling by pointing to the process of electronic dematerialization. But does this mean, that the move from the material to the dematerialized world of the electronic files lets itself easily analyzed by media archaeology - beyond exhibiting historical context of commonly used terminology of the computer world? According to Vismann: "The very terminology of computer surfaces is designed to remind users seated before screens of the familiar world of files. The menu tab offering options like »list», "format", "thesaurus ", "table" and the instructions copy, delete, save turn users into virtual chanceries or chancellors." (Vismann 163) Not the historical terminological background of such terms as "stacks, files, compiler, or registers" are of importance here, but the process Vismann draws our attention to, in which bureaucratic techniques sink from the state level to the individual one.

By condensing an entire administrative office, the computer implements the basic law of bureaucracy according to which administrative techniques are transferred from the state to the individual: from the specialized governmental practices of early modern chanceries to the »common style«, from absolutist administrative centers to individual work desks, from the first mainframe computers in defense ministries to the desktop at home. (Vismann 163)

Parikka points to a radically different, maybe even inverse process to make archives comprehendible in the $21^{\text {st }}$ century. Rather than tracing how official, central archiving practices preform everyday usage of the computer, in his first modelling gesture of $\mathrm{DCH}$ he compares archives to everyday social media practices.

However, with the emergence of such new social media 'archives' as YouTube, Flickr, etc., the notion of the bureaucratic archive has changed. Modes of accessing and storing data have changed from centrally governed and walled spaces to distributed and software-based. (...) In addition to the bureaucratic techniques of offices, the new archives have to take into account formats, 
medium-specificity, as well as various software-related themes such as encoding. Similarly, despite the distributed nature, one can argue that power still resides in the archive, which is now embedded in architectures of software, and the political economy of social media platforms whose revenue streams are based on the fact of individual everyday contributions through activity: Facebook, YouTube, Google, etc., gathering data on user patterns, preferences and consumer desires, for further evaluation, reuse and reselling purposes.

Parikka - maybe surprisingly - connects the process of the official archives going digital - with social media. So, this is the first model he proposes to disclose the darkness of the digital archive. He does not state explicitly that digital archives today function as web 2.0 practices, he only states that both are software related and physically-technologically shared. Still notable is the fact, that concrete examples of medium specificity come mainly from social media practices in this main part of the argumentation. Even more interesting is that notions of "centrally governed" and "distributed" are placed on opposite sides of a binary opposition. This contradiction suggests that a physically distributed digital architecture (like a distributed, cloud based computer system) - that is not confined to a single physical place and in this respect, cannot be allocated to a concrete physical space - were never centrally governed.

No doubt that new cultural practices of network society has a lot to do with the digital archive. But here a distinction should have to be made. Parikka's argument rightly points to the practical and theoretically relevant problem that contemporary memory institutions face an almost unsolvable but surely unavoidable challenge when they seek to deal with these new practices. How to select, handle, curate or archive them? The problem has a theoretical and a practical aspect as well: memory institutions developed musealizing, archiving, curatorial practices in an analogue world which are incapable of dealing with time-critical, processual media. And on the practical side: it is very complicated, almost impossible to archive a 'born digital' culture. "the theoretical problems of recent media archaeologies of technical media and software along with a rethinking of the archive, go hand in hand with the practical challenges faced by cultural heritage institutions and professionals: how do you archive processes and culture which is based on both technical processes (software and networks) and social ones (participation and collaboration, as in massive online role-playing platforms as cultural forms)." (Parikka 2012 115) But does this rightly staged problem mean that the digital archive of cultural heritage may be modelled through YouTube and Google?

There is another level of Parikka's argumentation concerning the digital archive, a more media archaeological - and more Vismannian one if you like: turning attention to the materiality of the medium. Media archaeology tends to concentrate on the hardware: 
For us, media is approached through the concrete artifacts, design solutions, and various technological layers that range from hardware to software processes, each of which in its own way participates in the circulation of time and memory. The medium is an archive in the Foucauldian sense as a condition of knowledge, but also as a condition of perceptions, sensations, memory, and time. (...) a special emphasis is placed on hardware even if we do not wish to claim that it is the only aspect about media and obsolescence we should consider. (Parikka 2015 146)

Parikka - following Wendy Hui Kyong Chun's work on the enduring ephemeral (Chun), includes the decay, the vulnerability, of the digital medium and its material carrier into the argumentation from both symbolic and material aspects of archiving. $\mathrm{He}$ challenges the illusion that 'remediation' of the digital media, the so called "digitalisation" would serve as the final solution to avoid decay of material inscriptions of cultural memory. Museologists and archivists are facing the consequences of this illusion radically when CD-s - meant to be the utmost means of digital eternity - become inaccessible overnight. A productive aspect may indeed be to stage official digital archives as they fight and hide this vulnerability - but this step from the danger of decay to the archival mission of the official institutes is not done here.

Another point where Parikka sheds light to the material aspects of the digital archive is also rather Vismannian: staging digital inscription as the inheritor to analogue writing acts. And still, it is not obviously convincing to model the digital archives on the basis of a however inventive analysis of the writing act: the inscription of the hard drive. He evokes Matthew G. Kirschenbaum and his forensic methodology based argumentation and implies that screen essentialism - when the medium is understood solely by focusing on the visual interface - in the realm of the digital archive can be transcended by going "below", into the depth, down to the digital inscription on the hard drive. „Kirschenbaum focuses on inscription, but in doing so is able to question the dilemmas concerning the so often preferred screen-essentialism, (...). Indeed, the idea of forensics suits both practically and epistemologically, the media-archaeological idea of going deeper and deeper into the materiality of the informational systems." (Parikka 2012 127) No doubt, that traditional archives, museums and collectors are highly interested in the physical inscriptions on material platforms of born digital manuscripts, net art artworks or software. The Literaturarchiv Marbach invested countless creativity and manpower to archive and curate Friedrich Kittler's digital heritage (Enge and Kramski). But does this mean that official memory institutions or digital archives could be modelled focusing on the material inscription of their informational systems that actually provides technological and institutional framework for the whole process of archiving? To be cynical for a moment: as if the technical 
and institutional machinery of the traditional archive could be made comprehendible through a focus on the process of the ink absorbed by paper stored in the repository in the basement.

Parikka's argumentation does not leave the space between the surfaces of the screen and the digital inscription that takes place in (or is hidden by) the digital archive empty, but from the practices he uses to enlighten this shadowy sub-medial space (artistic and social media practice of the network society) official digital archival mechanisms are strangely missing. Anything that is "centrally governed". Although these, rightly or not, often define and even legitimate themselves against the "ephemeral" and "chaotic" nature of the unofficial, like social media communication and also popular/commercial sharing services. There is of course overlapping of the official archive and the social media practice (one good example is crowdsourcing), but this does not mean that the difference in the machinery of the two could be bypassed.

I wouldn't say that it was easy to give a media archaeological account of the formal-institutional digital media practices. What I would only point to is that the aspects that make such an account deep enough are missing from Parikka's detailed analysis of digital heritage. Although if one takes a closer look they are not entirely missing: "the new archives have to take into account formats, medium-specificity, as well as various software-related themes such as encoding" (Parikka 2012 115) and Parikka also quotes a study that quotes Kirschenbaum:

"A bibliographic/textual approach calls upon us to emphasize precisely those aspects of electronic textuality that have thus far been neglected in the critical writing about the medium: platform, interface, data standards, file formats, operating systems, versions and distributions of code, patches, ports, and so forth. For that's the stuff electronic texts are made of." (Parikka 20123 85) But he does not have anything to say on how digital cultural heritage is conditioned by, say, data standards, modes of encoding or code versioning. This blind spot makes Parikka's argumentation on such special sub-fields of digital cultural heritage as digital philology especially vulnerable.

An average user won't get through the graphical user interface, so the chance to move beyond screen essentialism is rather low. Some text archives provide access to the encoded text, the text encoded in a mark-up language, but this language - designed to be machine readable and that is comprehendible only to trained digital humanists forms a rather high door-step. The transformations that are constitutional on the level of the archival machinery, that create the images present on the screen based on the encoded text, and the ones that connect the code to the material inscription on the storage surface, are hidden to digital humanists as well, either by authorization limitations or because of the lack of specific IT knowledge. 
If so, is it possible at all to provide a deep and material media archaeology of, say, a scholarly textarchive as TextGrid or Deutsches Textarchiv? There are chances of a however partial insight into the dark space between the screen of the user interface and depth of the material inscription by reading specifications provided by the project team, by analyzing the used metadata scheme, the encoding principles and the implemented search query language. Sure, without reflecting upon this level of archival machinery the sub-medial won't let itself enlightened. In this respect Parikka fails to give a proper media archaeological account on official digital media practices. If it is possible at all, it remains an open question in a digital infrastructure where material inscription is moved from the material interface of a single hard drive to a cloud computing environment, where the writing act is hidden by a software architecture continuously evolving itself.

\section{Works Cited}

Bolter, Jay David, and Richard Grusin. Remediation. Understanding New Media. The MIT Press, 1999.

Castells, Manuel. The Rise of the Network Society. Wiley-Blackwell, 2012.

Chun, Wendy Hui Kyong. "The Enduring Ephemeral or The Future Is a Memory." Media Archaeology. Approaches, Applications, Implications, edited by Erkki Huhtamo and Jussi Parikka, University of California Press, 184-203.

Enge, Jürgen, and Kramski, Heinz Werner. "Friedrich Kittler's Digital Legacy - PART I Challenges, Insights and Problem-Solving Approaches in the Editing of Complex Digital Data Collections." Digital Humanities Quarterly, 2017.

Ernst, Wolfgang. Das Rumoren der Archive. Ordnung aus Unordnung. Merve Verlag, 2002.

Farge, Arlette. "The Allure of the Archives." The Lewis Walpole Series in EighteenthCentury Culture and History. Translated by Thomas Scott-Railton, foreword by Natalie Zemon Davis, Yale UP, 2013.

Groys, Boris. Unter Verdacht. Eine Phänomenologie der Medien. Hanser, 2000.

Parikka, Jussi. "A Geology of Media." Electronic Mediations, Volume 46, Minnesota UP, 2015.

Parikka, Jussi. "Archive Dynamics: Software Culture and Digital Heritage." What is Media Archaeology. Polity, 2012, 113-135.

Vismann, Cornelia. Files. Law and Media Technology. Translated by Geoffrey WinthropYoung, Stanford UP, 2008. 